\title{
Fixed Points of Multivalued Contractive Mappings in Partial Metric Spaces
}

\author{
Abdul Rahim Khan, ${ }^{1}$ Mujahid Abbas, ${ }^{2}$ Talat Nazir, ${ }^{3}$ and Cristiana Ionescu ${ }^{4}$ \\ ${ }^{1}$ Department of Mathematics and Statistics, King Fahd University of Petroleum and Minerals, Dhahran 31261, Saudi Arabia \\ ${ }^{2}$ Department of Mathematics and Applied Mathematics, University Pretoria, Lynnwood Road, Pretoria 0002, South Africa \\ ${ }^{3}$ Department of Mathematics, COMSATS Institute of Information Technology, Abbottabad 22060, Pakistan \\ ${ }^{4}$ Faculty of Applied Sciences, University Politehnica of Bucharest, 313 Splaiul Independentei, 060042 Bucharest, Romania
}

Correspondence should be addressed to Cristiana Ionescu; cristianaionescu58@yahoo.com

Received 23 November 2013; Accepted 7 January 2014; Published 20 February 2014

Academic Editor: Hassen Aydi

Copyright (C) 2014 Abdul Rahim Khan et al. This is an open access article distributed under the Creative Commons Attribution License, which permits unrestricted use, distribution, and reproduction in any medium, provided the original work is properly cited.

The aim of this paper is to present fixed point results of multivalued mappings in the framework of partial metric spaces. Some examples are presented to support the results proved herein. Our results generalize and extend various results in the existing literature. As an application of our main result, the existence and uniqueness of bounded solution of functional equations arising in dynamic programming are established.

\section{Introduction}

In 1922, Banach proved his celebrated contraction principle [1]. As it is well known, there have been published remarkable research articles about fixed points theory for different classes of contractive mappings, on some spaces such as quasi-metric spaces [2], cone metric spaces [3], convex metric spaces [4], partially ordered metric spaces [5-10], G-metric spaces [1115], partial metric spaces [16, 17], quasi-partial metric spaces [18], fuzzy metric spaces [19], and Menger spaces [20]. Also, studies either on approximate fixed point or on qualitative aspects of numerical procedures for approximating fixed points are available in literature; please, see [4, 21-23].

The concept of a partial metric space is introduced by Matthews [24], as a part of the study of denotational semantics of dataflow networks. He gave a modified version of the Banach contraction principle, more suitable in this context (see also $[25,26]$ ). In fact, (complete) partial metric spaces constitute a suitable framework to model several distinguished examples of the theory of computation and also to model metric spaces via domain theory (see [24, 27-31]).

It was shown that, in some cases, the results of fixed point in partial metric spaces can be obtained directly from their induced metric counterparts [32-34]. However, some conclusions important for the application of partial metrics in information sciences cannot be obtained in this way. For example, if $x$ is a fixed point of map $f$, then, by using the method from [32], we cannot conclude that $p(f x, f x)=0=$ $p(x, x)$. For further details, we refer the reader to $[35,36]$.

Recently, Aydi et al. [37] introduced the concept of a partial Hausdorff metric. They initiated study of fixed point theory for multivalued mappings on partial metric space using the partial Hausdorff metric and proved an analogue of the well-known Nadler fixed point theorem.

In this paper, we obtain several fixed point results of multivalued mappings in partial metric spaces. Our results extend, unify, and generalize the comparable results in [3841].

\section{Preliminaries}

In the sequel the letters $\mathbb{R}, \mathbb{R}^{+}$, and $\mathbb{N}^{*}$ will denote the set of all real numbers, the set of all nonnegative real numbers, and the set of all positive integer numbers, respectively.

Consistent with $[24,42]$, the following definitions and results will be needed in the sequel. 
Definition 1. Let $X$ be a nonempty set. A function $p: X \times$ $X \rightarrow \mathbb{R}^{+}$is said to be a partial metric on $X$ if, for any $x, y, z \in$ $X$, the following conditions hold:

$$
\begin{aligned}
& \left(\mathrm{p}_{1}\right) p(x, x)=p(y, y)=p(x, y) \text { if and only if } x=y ; \\
& \left(\mathrm{p}_{2}\right) p(x, x) \leq p(x, y) \\
& \left(\mathrm{p}_{3}\right) p(x, y)=p(y, x) \\
& \left(\mathrm{p}_{4}\right) p(x, z) \leq p(x, y)+p(y, z)-p(y, y) .
\end{aligned}
$$

The pair $(X, p)$ is called a partial metric space.

If $p(x, y)=0$, then $\left(\mathrm{p}_{1}\right)$ and $\left(\mathrm{p}_{2}\right)$ imply that $x=y$. But the converse does not hold in general.

A trivial example of a partial metric space is the pair $\left(\mathbb{R}^{+}, p\right)$, where

$$
p: \mathbb{R}^{+} \times \mathbb{R}^{+} \longrightarrow \mathbb{R}^{+}, \quad p(x, y)=\max \{x, y\} .
$$

Example 2 (see [24]). If $X=\{[a, b]: a, b \in \mathbb{R}, a \leq b\}$, then

$$
p([a, b],[c, d])=\max \{b, d\}-\min \{a, c\}
$$

defines a partial metric $p$ on $X$.

For more examples of partial metric spaces, we refer to $[17,29,31,43-45]$.

Each partial metric $p$ on $X$ generates a $T_{0}$ topology $\tau_{p}$ on $X$, whose base is the family of open $p$-balls $\left\{B_{p}(x, \varepsilon): x \in\right.$ $X, \varepsilon>0\}$, where $B_{p}(x, \varepsilon)=\{y \in X: p(x, y)<p(x, x)+\varepsilon\}$, for all $x \in X$ and $\varepsilon>0$.

Observe (see [24, p. 187]) that a sequence $\left\{x_{n}\right\}$ in a partial metric space $(X, p)$ converges to a point $x \in X$, with respect to $\tau_{p}$, if and only if $p(x, x)=\lim _{n \rightarrow \infty} p\left(x, x_{n}\right)$.

If $p$ is a partial metric on $X$, then the function

$$
\begin{gathered}
p^{S}: X \times X \longrightarrow \mathbb{R}^{+}, \\
p^{S}(x, y)=2 p(x, y)-p(x, x)-p(y, y),
\end{gathered}
$$

defines a metric on $X$.

Furthermore, a sequence $\left\{x_{n}\right\}$ converges in $\left(X, p^{S}\right)$ to a point $x \in X$ if and only if

$$
\lim _{n, m \rightarrow \infty} p\left(x_{n}, x_{m}\right)=\lim _{n \rightarrow \infty} p\left(x_{n}, x\right)=p(x, x) .
$$

Definition 3 (see $[24])$. Let $(X, p)$ be a partial metric space.

(a) A sequence $\left\{x_{n}\right\}$ in $X$ is said to be a Cauchy sequence if $\lim _{n, m \rightarrow \infty} p\left(x_{n}, x_{m}\right)$ exists and is finite.

(b) $(X, p)$ is said to be complete if every Cauchy sequence $\left\{x_{n}\right\}$ in $X$ converges with respect to $\tau_{p}$ to a point $x \in X$ such that $\lim _{n \rightarrow \infty} p\left(x, x_{n}\right)=p(x, x)$. In this case, we say that the partial metric $p$ is complete.

Lemma 4 (see $[24,42])$. Let $(X, p)$ be a partial metric space. Then,

(i) a sequence $\left\{x_{n}\right\}$ in $X$ is a Cauchy sequence in $(X, p)$ if and only if it is a Cauchy sequence in metric space $\left(X, p^{S}\right)$; (ii) a partial metric space $(X, p)$ is complete if and only if the metric space $\left(X, p^{S}\right)$ is complete.

Let $(X, p)$ be a partial metric space. Let $P(X)$ and $P_{c l}(X)$ $\left(P_{C B}(X)\right)$ be the family of all nonempty and nonempty and closed (nonempty, closed, and bounded) subsets of the partial metric space $(X, p)$. Note that here closedness is considered in $\left(X, \tau_{p}\right)\left(\tau_{p}\right.$ is the topology induced by $\left.p\right)$ while boundedness is given as follows: $A$ is a bounded subset in $(X, p)$ if there exist $x_{0} \in X$ and $M \geq 0$ such that, for all $a \in A$, we have $a \in B_{p}\left(x_{0}, M\right)$; that is, $p\left(x_{0}, a\right)<p(a, a)+M$.

For $A, B \in P_{C B}(X)$ and $x \in X$, [37] defines

$$
\begin{aligned}
p(x, A) & =\inf \{p(x, a), a \in A\}, \\
\delta_{p}(A, B) & =\sup \{p(a, B): a \in A\}, \\
\delta_{p}(B, A) & =\sup \{p(b, A): b \in B\} .
\end{aligned}
$$

It is easy to check that $p(x, A)=0 \Rightarrow p^{S}(x, A)=0$, where $p^{S}(x, A)=\inf \left\{p^{S}(x, a), a \in A\right\}$.

Remark 5 (see [42]). Let $(X, p)$ be a partial metric space and let $A$ be any nonempty set in $(X, p)$. Then

$$
a \in \bar{A} \quad \text { iff } p(a, A)=p(a, a)
$$

where $\bar{A}$ denotes the closure of $A$ with respect to the partial metric $p$. Note that $A$ is closed in $(X, p)$ if and only if $A=\bar{A}$.

Let $X$ be any nonempty set and let $T: X \rightarrow P(X)$ be a given mapping. For any fixed $x_{0} \in X$, a sequence $\left\{x_{n}\right\}$ in $X$ such that $x_{n+1} \in T\left(x_{n}\right)$ is called a $T$-orbital sequence about $x_{0}$. Collection of all such sequences will be denoted by $O\left(T, x_{0}\right)$. Further a point $z \in X$ is called a fixed point of $T$ if and only if $z \in T(z)$ [46]. The set of all fixed points of multivalued mapping $T$ is denoted by $F(T)$.

We have the following partial metric space version of Definition 1.8 in [47].

Definition 6. Let $X$ be any nonempty set, $x_{0}, z \in X$, and let $T: X \rightarrow P(X)$. A mapping $f: X \rightarrow \mathbb{R}$ is said to be T-orbitally lower semicontinuous at $z$ with respect to $x_{0}$ if $\left\{x_{n}\right\} \in O\left(T, x_{0}\right)$ and $x_{n}$ converges to $z$ implying that $f(z) \leq \liminf _{n \rightarrow \infty} f\left(x_{n}\right)$.

\section{Fixed Points of Multivalued Mapping}

In this section, we obtain several fixed point results of multivalued mappings satisfying more general contractive conditions than those of Cho et al. [47], Ćirić [48], and Feng and Liu [38] in the frame work of partial metric spaces.

Theorem 7. Let $X$ be a partial metric space and let $T: X \rightarrow$ $P_{c l}(X)$ be a multivalued mapping. Suppose that there exist 
functions $\phi:[0, \infty) \rightarrow[0,1)$ and $\psi:[0, \infty) \rightarrow[c, 1]$ such that

$$
\begin{gathered}
\phi(t)<\psi(t) \quad \forall t \in[0, \infty), \\
\limsup _{t \rightarrow r^{+}} \frac{\phi(t)}{\psi(t)}<1 \quad \forall r \in[0, \infty),
\end{gathered}
$$

where $c \in(0,1)$. If, for any $x \in X$, there exists $y \in T(x)$ satisfying

$$
\begin{aligned}
& \psi(p(x, y)) p(x, y) \leq p(x, T(x)), \\
& p(y, T(y)) \leq \phi(p(x, y)) p(x, y),
\end{aligned}
$$

then, for each $x_{0} \in X$, there exists $\left\{x_{n}\right\}$ in $O\left(T, x_{0}\right)$ such that $\left\{x_{n}\right\}$ is Cauchy sequence. Further, if $\left\{x_{n}\right\}$ converges to $z$ and the function $f(x)=p(x, T(x))$ is T-orbitally lower semicontinuous at $z$ with respect to $x_{0}$, then $z$ is a fixed point of $T$. If $T(z)=\{z\}$, then $p(z, z)=0$.

Proof. Let $x_{0}$ be a given point in $X$. Since $T\left(x_{0}\right) \in P_{c l}(X)$, we can choose $x_{1} \in T\left(x_{0}\right)$ such that

$$
\begin{aligned}
& \psi\left(p\left(x_{0}, x_{1}\right)\right) p\left(x_{0}, x_{1}\right) \leq p\left(x_{0}, T\left(x_{0}\right)\right), \\
& p\left(x_{1}, T\left(x_{1}\right)\right) \leq \phi\left(p\left(x_{0}, x_{1}\right)\right) p\left(x_{0}, x_{1}\right) .
\end{aligned}
$$

Then, we have

$$
p\left(x_{1}, T\left(x_{1}\right)\right) \leq \frac{\phi\left(p\left(x_{0}, x_{1}\right)\right)}{\psi\left(p\left(x_{0}, x_{1}\right)\right)} p\left(x_{0}, T\left(x_{0}\right)\right) .
$$

We define $\mu:[0, \infty) \rightarrow[0, \infty)$ by $\mu(t)=\phi(t) / \psi(t)$ for all $t \in$ $[0, \infty)$. Then by definition of $\phi$ and $\psi$, it follows that $\mu(t)<1$ for all $t \in[0, \infty)$ and $\lim \sup _{t \rightarrow r^{+}} \mu(t)<1$ for all $r \in[0, \infty)$. From (11), we have

$$
p\left(x_{1}, T\left(x_{1}\right)\right) \leq \mu\left(p\left(x_{0}, x_{1}\right)\right) p\left(x_{0}, T\left(x_{0}\right)\right) .
$$

Continuing this way, we can obtain a sequence $\left\{x_{n}\right\}$ in $X$ such that $x_{n+1} \in T\left(x_{n}\right)$ which satisfies

$$
\begin{array}{r}
\psi\left(p\left(x_{n}, x_{n+1}\right)\right) p\left(x_{n}, x_{n+1}\right) \leq p\left(x_{n}, T\left(x_{n}\right)\right), \\
p\left(x_{n+1}, T\left(x_{n+1}\right)\right) \leq \phi\left(p\left(x_{n}, x_{n+1}\right)\right) p\left(x_{n}, x_{n+1}\right) .
\end{array}
$$

Now by (13) and (14), we have

$$
p\left(x_{n+1}, T\left(x_{n+1}\right)\right) \leq \mu\left(p\left(x_{n}, x_{n+1}\right)\right) p\left(x_{n}, T\left(x_{n}\right)\right) \text {. }
$$

As $\mu(t)<1$, we have

$$
p\left(x_{n+1}, T\left(x_{n+1}\right)\right)<p\left(x_{n}, T\left(x_{n}\right)\right),
$$

for all $n \geq 0$. Thus, $\left\{p\left(x_{n}, T\left(x_{n}\right)\right)\right\}$ is (strictly) decreasing sequence of positive real numbers. Consequently, there exists $\alpha \geq 0$ such that $\left\{p\left(x_{n}, T\left(x_{n}\right)\right)\right\}$ converges to $\alpha$. Since $0<c \leq$ $\psi(t)$ for all $t \in[0, \infty)$, it follows from (13) that $c p\left(x_{n}, x_{n+1}\right) \leq$ $\psi\left(p\left(x_{n}, x_{n+1}\right)\right) p\left(x_{n}, x_{n+1}\right) \leq p\left(x_{n}, T\left(x_{n}\right)\right)$, and hence we have

$$
0 \leq p\left(x_{n}, x_{n+1}\right) \leq \frac{1}{c} p\left(x_{n}, T\left(x_{n}\right)\right) .
$$

On taking upper limit as $n \rightarrow \infty$ on both sides of (17), we have

$$
\alpha \leq \limsup _{n \rightarrow \infty} \mu\left(p\left(x_{n}, x_{n+1}\right)\right) \alpha,
$$

which implies that $\alpha=0$; that is, $\lim _{n \rightarrow \infty} p\left(x_{n}, T\left(x_{n}\right)\right)=0$.

Now we show that $\left\{x_{n}\right\}$ is a Cauchy sequence. Put $\gamma=\lim \sup _{p\left(x_{n}, x_{n+1}\right) \rightarrow 0^{+}} \mu\left(p\left(x_{n}, x_{n+1}\right)\right)$. We can choose a real number $k \in[\gamma, 1)$ such that there exists a positive integer $n_{1}$ such that $\mu\left(p\left(x_{n}, x_{n+1}\right)\right) \leq k$ for all $n \geq n_{1}$. Thus, from (15), we have $p\left(x_{n}, T\left(x_{n}\right)\right) \leq k p\left(x_{n-1}, T\left(x_{n-1}\right)\right)$ for all $n \geq n_{1}$. So for all $m, n \in \mathbb{N}$ with $m>n \geq n_{1}+1$,

$$
p\left(x_{m}, T\left(x_{m}\right)\right) \leq k^{m-n} p\left(x_{n-1}, T\left(x_{n-1}\right)\right) .
$$

Also, from (17) and (19), we have

$$
p\left(x_{m}, x_{m+1}\right) \leq \frac{k^{m-n}}{c} p\left(x_{n-1}, T\left(x_{n-1}\right)\right)
$$

for all $m>n>n_{1}+1$. Now

$$
\begin{aligned}
p^{S} & \left(x_{m}, x_{m+1}\right) \\
& =2 p\left(x_{m}, x_{m+1}\right)-p\left(x_{m}, x_{m}\right)-p\left(x_{m+1}, x_{m+1}\right) \\
& \leq 2 p\left(x_{m}, x_{m+1}\right)+p\left(x_{m}, x_{m}\right)+p\left(x_{m+1}, x_{m+1}\right) \\
& \leq 4 p\left(x_{m}, x_{m+1}\right) \leq \frac{4}{c} k^{m-n} p\left(x_{n-1}, T\left(x_{n-1}\right)\right) .
\end{aligned}
$$

Thus

$$
\begin{aligned}
p^{S} & \left(x_{n}, x_{m}\right) \\
& \leq p^{S}\left(x_{n}, x_{n+1}\right)+p^{S}\left(x_{n+1}, x_{n+2}\right)+\cdots+p^{S}\left(x_{m-1}, x_{m}\right) \\
& \leq \frac{4}{c}\left[k+k^{2}+\cdots k^{m-n-1}\right] p\left(x_{n-1}, T\left(x_{n-1}\right)\right) \\
& \leq \frac{4}{c}\left(\frac{1}{1-k}\right) p\left(x_{n-1}, T\left(x_{n-1}\right)\right),
\end{aligned}
$$

for all $m>n \geq n_{1}+1$. Using $\lim _{n \rightarrow \infty} p\left(x_{n-1}, T\left(x_{n-1}\right)\right)=0$, we get that $\left\{x_{n}\right\}$ is a Cauchy sequence in the metric space $\left(O\left(T, x_{0}\right), p^{S}\right)$. By Lemma $4,\left\{x_{n}\right\}$ is a Cauchy sequence in $\left(O\left(T, x_{0}\right), p\right)$.

Next, we assume that there exists an element $z$ in $O\left(T, x_{0}\right)$ such that

$$
p(z, z)=\lim _{n \rightarrow \infty} p\left(x_{n}, z\right)=\lim _{n, m \rightarrow \infty} p\left(x_{n}, x_{m}\right)
$$

and the function $p(x, T(x))$ is $T$-orbitally lower semicontinuous at $z$ with respect to $x_{0}$. Then it follows that

$$
\begin{aligned}
0 & \leq p(z, T(z)) \\
& \leq \liminf _{n \rightarrow \infty} p\left(x_{n}, T\left(x_{n}\right)\right) \\
& \leq \lim _{n \rightarrow \infty} p\left(x_{n}, T\left(x_{n}\right)\right)=0 .
\end{aligned}
$$

Thus $p(z, T(z))=0$. Since $T(z)$ is closed, $z \in T(z)$. 
Now, if $T(z)=\{z\}$, then from (9) we have

$$
0 \leq p(z, z)=p(z, T(z)) \leq \phi(p(z, z)) p(z, z),
$$

where $\phi(p(z, z))<1$. Hence $p(z, z)=0$.

Example 8. Let $X=\{1,2,3\}$ and let $p: X \times X \rightarrow \mathbb{R}^{+}$be the partial metric defined by

$$
\begin{gathered}
p(1,1)=\frac{1}{4}, \quad p(2,2)=p(3,3)=0, \\
p(1,2)=p(2,1)=\frac{11}{24}, \\
p(1,3)=p(3,1)=\frac{1}{2}, \\
p(2,3)=p(3,2)=\frac{1}{3} .
\end{gathered}
$$

Define the mapping $T: X \rightarrow P_{c l}(X)$ by

$$
T x= \begin{cases}\{2\} & \text { if } x \in\{2,3\}, \\ \{2,3\} & \text { if } x=1 .\end{cases}
$$

Note that $T x$ is closed and bounded for all $x \in X$ in the partial metric space $(X, p)$. Define $\phi:[0, \infty) \rightarrow[0,1)$ and $\psi:[0, \infty) \rightarrow[c, 1]$, where $c \in(0,1)$ as

$$
\begin{aligned}
& \phi(t)= \begin{cases}\frac{t}{8} & \text { if } t \in[0,4), \\
\frac{1}{2} & \text { if } t \geq 4,\end{cases} \\
& \psi(t)= \begin{cases}\frac{1}{6} & \text { if } t=0, \\
\frac{t}{4} & \text { if } t \in(0,4), \\
1 & \text { if } t \geq 4 .\end{cases}
\end{aligned}
$$

Clearly, $\phi(t)<\psi(t)$ for all $t \in[0, \infty)$ and $\lim \sup _{t \rightarrow r^{+}}(\phi(t) / \psi(t))<1$ for all $r \in[0, \infty)$. We will show that for all $x, y \in X,(8)$ and (9) are satisfied. For this, we consider the following cases.

(i) If $x=1$, then there exists $y=2 \in T(1)$ such that

$$
\begin{aligned}
\psi(p(x, y)) p(x, y) & =\psi(p(1,2)) p(1,2)=\frac{121}{2304} \\
& <\frac{11}{24}=p(1,\{2,3\})=p(x, T(x)), \\
p(y, T(y)) & =p(2,\{2\})=0 \\
& <\frac{121}{4608}=\phi(p(1,2)) p(1,2) \\
& =\phi(p(x, y)) p(x, y) .
\end{aligned}
$$

(ii) When $x=2$, then there exists $y=2 \in T(2)$ such that

$$
\begin{aligned}
\psi(p(x, y)) p(x, y) & =\psi(p(2,2)) p(2,2)=0 \\
& =p(2,\{2\})=p(x, T(x)), \\
p(y, T(y)) & =p(2,\{2\})=0 \\
& =\phi(p(2,2)) p(2,2) \\
& =\phi(p(x, y)) p(x, y) .
\end{aligned}
$$

(iii) For $x=3$, there exists $y=2 \in T(1)$ such that

$$
\begin{aligned}
\psi(p(x, y)) p(x, y) & =\psi(p(3,2)) p(3,2)=\frac{1}{36} \\
& <\frac{1}{3}=p(3,\{2\})=p(x, T(x)), \\
p(y, T(y)) & =p(2,\{2\})=0 \\
& <\frac{1}{72}=\phi(p(3,2)) p(3,2) \\
& =\phi(p(x, y)) p(x, y) .
\end{aligned}
$$

Thus, all the conditions of Theorem 7 are satisfied. Moreover, $T(2)=\{2\}$ and $p(2,2)=0$.

The next example shows that one cannot derive the conclusion of Theorem 7 using metric induced by a partial metric.

Example 9. Let $X=\mathbb{R}^{+}$be the partial metric space with $p(x, y)=\max \{x, y\}$. Define the mapping $T: X \rightarrow P_{c l}(X)$ by

$$
T x= \begin{cases}{\left[0, \frac{7 x}{8}\right]} & \text { if } x \in[0,1] \\ \left\{\frac{1}{2}\right\} & \text { if } x>1\end{cases}
$$

Note that $T x$ is closed and bounded for all $x \in X$ in the partial metric space $(X, p)$. Define $\phi:[0, \infty) \rightarrow[0,1)$ and $\psi:[0, \infty) \rightarrow[c, 1]$ by

$$
\begin{aligned}
& \phi(t)= \begin{cases}\frac{t}{8} & \text { if } t \in[0,1), \\
\frac{1}{2} & \text { if } t \geq 1,\end{cases} \\
& \psi(t)= \begin{cases}\frac{1}{6} & \text { if } t=0, \\
\frac{t}{4} & \text { if } t \in(0,1), \\
1 & \text { if } t \geq 1,\end{cases}
\end{aligned}
$$

where $c \in(0,1)$. Clearly, $\phi(t)<\psi(t)$ for all $t \in[0, \infty)$ and $\lim \sup _{t \rightarrow r^{+}}(\phi(t) / \psi(t))<1$ for all $r \in[0, \infty)$. We will show 
that, for all $x, y \in X,(8)$ and (9) are satisfied. For this, we consider the following cases.

When $x=0$, then, for $y=0 \in T(x),(8)$ and (9) are satisfied.

For $x \in(0,1]$, take $y=x / 2 \in T(x)$ such that

$$
\begin{aligned}
\psi(p(x, y)) p(x, y) & =\psi\left(p\left(x, \frac{x}{2}\right)\right) p\left(x, \frac{x}{2}\right)=\frac{x^{2}}{4} \\
& <x=p\left(x,\left[0, \frac{7 x}{8}\right]\right)=p(x, T(x)), \\
p(y, T(y)) & =p\left(\frac{x}{2},\left[0, \frac{7 x}{8}\right]\right)=\frac{x}{2} \\
& <\frac{x^{2}}{8}=\phi\left(p\left(x, \frac{x}{2}\right)\right) p\left(x, \frac{x}{2}\right) \\
& =\phi(p(x, y)) p(x, y) .
\end{aligned}
$$

In case $x>1$, taking $y=1 / 2 \in T(x)$, we have

$$
\begin{aligned}
\psi(p(x, y)) p(x, y) & =\psi\left(p\left(x, \frac{1}{2}\right)\right) p\left(x, \frac{1}{2}\right) \\
& =x=p\left(x,\left[0, \frac{7 x}{8}\right]\right)=p(x, T(x)), \\
p(y, T(y)) & =p\left(\frac{1}{2},\left[0, \frac{7}{16}\right)\right)=\frac{1}{2} \\
& <\frac{x}{2}=\phi\left(p\left(x, \frac{1}{2}\right)\right) p\left(x, \frac{1}{2}\right) \\
& =\phi(p(x, y)) p(x, y) .
\end{aligned}
$$

Hence for all $x \in X$, there exists $y \in T(x)$ such that (8) and (9) are satisfied. Thus, all the conditions of Theorem 7 are satisfied. Moreover, $T(0)=\{0\}$ and $p(0,0)=0$.

On the other hand, we have $p^{S}(x, y)=|x-y|$. If we take $x \in(1 / 2,1)$, then there does not exist any $y \in T(x)$ such that (8) and (9) are satisfied.

Hence we are justified in formulating the following result.

Theorem 10. Let $X$ be a partial metric space and let $T$ : $X \rightarrow P_{c l}(X)$ be a mapping. Suppose that there exist functions $\phi:[0, \infty) \rightarrow[0,1), \psi:[0, \infty) \rightarrow[c, 1]$ such that

$$
\begin{gathered}
\phi(t)<\psi(t) \quad \forall t \in[0, \infty), \\
\limsup _{t \rightarrow r^{+}} \frac{\phi(t)}{\psi(t)}<1 \quad \forall r \in[0, \infty),
\end{gathered}
$$

where $c \in(0,1)$. If for any $x \in X$ there exists $y \in T(x)$ satisfying

$$
\begin{aligned}
& \psi(p(x, T(x))) p(x, y) \leq p(x, T(x)), \\
& p(y, T(y)) \leq \phi(p(x, T(x))) p(x, y),
\end{aligned}
$$

then, for each $x_{0} \in X$, there exists $\left\{x_{n}\right\}$ in $O\left(T, x_{0}\right)$ such that $\left\{x_{n}\right\}$ is a Cauchy sequence. Further, if $\left\{x_{n}\right\}$ converges to $z$ and the function $f(x)=p(x, T(x))$ is T-orbitally lower semicontinuous at $z$ with respect to $x_{0}$, then $z \in F(T)$.

Proof. Let $x_{0}$ be a given point in $X$. As in the proof of Theorem 7, we can obtain a sequence $\left\{x_{n}\right\}$ in $X$ such that $x_{n+1} \in T\left(x_{n}\right)$, which satisfies

$$
\begin{gathered}
\psi\left(p\left(x_{n}, T\left(x_{n}\right)\right)\right) p\left(x_{n}, x_{n+1}\right) \leq p\left(x_{n}, T\left(x_{n}\right)\right), \\
p\left(x_{n+1}, T\left(x_{n+1}\right)\right) \leq \phi\left(p\left(x_{n}, T\left(x_{n}\right)\right)\right) p\left(x_{n}, x_{n+1}\right) .
\end{gathered}
$$

From $\mu(t)=\phi(t) / \psi(t)$ for all $t \in[0, \infty)$, we have

$$
p\left(x_{n+1}, T\left(x_{n+1}\right)\right) \leq \mu\left(p\left(x_{n}, T\left(x_{n}\right)\right)\right) p\left(x_{n}, T\left(x_{n}\right)\right) .
$$

As $\mu(t)<1$, so we have

$$
p\left(x_{n+1}, T\left(x_{n+1}\right)\right)<p\left(x_{n}, T\left(x_{n}\right)\right),
$$

for all $n \geq 0$, and it follows that $\left\{p\left(x_{n}, T\left(x_{n}\right)\right)\right\}$ is (strictly) decreasing sequence of positive real numbers. Consequently, there exists $\beta \geq 0$ such that $\left\{p\left(x_{n}, T\left(x_{n}\right)\right)\right\}$ converges to $\beta$. On taking upper limit as $n \rightarrow \infty$ on both sides of (40), we have

$$
\beta \leq \limsup _{n \rightarrow \infty} \mu\left(p\left(x_{n}, T\left(x_{n}\right)\right)\right) \beta,
$$

which implies that $\beta=0$; that is, $\lim _{n \rightarrow \infty} p\left(x_{n}, T\left(x_{n}\right)\right)=0$.

Now we show that $\left\{x_{n}\right\}$ is a Cauchy sequence. Since $0<$ $c \leq \psi(t)$, for all $t \in[0, \infty)$, it follows from (38) that $c p\left(x_{n}, x_{n+1}\right) \leq \psi\left(p\left(x_{n}, T\left(x_{n}\right)\right)\right) p\left(x_{n}, x_{n+1}\right) \leq p\left(x_{n}, T\left(x_{n}\right)\right)$, and hence we have

$$
0 \leq p\left(x_{n}, x_{n+1}\right) \leq \frac{1}{c} p\left(x_{n}, T\left(x_{n}\right)\right) .
$$

Thus the sequence $\left\{p\left(x_{n}, x_{n+1}\right)\right\}$ is bounded.

Following arguments similar to those in the proof of Theorem 7, we obtain that $\left\{x_{n}\right\}$ is a Cauchy sequence in $\left(O\left(T, x_{0}\right), p\right)$ and $z \in T(z)$.

Now, in the next two results, we consider further generalization of the conditions (8), (9), and (37).

Theorem 11. Let $X$ be a partial metric space and let $T$ : $X \rightarrow P_{c l}(X)$ be a multivalued mapping. Suppose that there exist functions $\phi:[0, \infty) \rightarrow[0, \infty), \psi:[0, \infty) \rightarrow(0, \infty)$ such that $\phi$ is nondecreasing and subadditive and they satisfy

$$
\begin{gathered}
\phi(t)<\psi(t) \quad \forall t \in[0, \infty), \\
\limsup _{t \rightarrow r^{+}} \frac{\phi(t)}{\psi(t)}<1 \quad \forall r \in[0, \infty) .
\end{gathered}
$$

If for any $x \in X$ there exists $y \in T(x)$ satisfying

$$
\begin{aligned}
& \psi(p(x, y)) \leq p(x, T(x)), \\
& p(y, T(y)) \leq \phi(p(x, y)),
\end{aligned}
$$

then, for each $x_{0} \in X$, there exists $\left\{x_{n}\right\}$ in $O\left(T, x_{0}\right)$ such that $\left\{x_{n}\right\}$ is a Cauchy sequence. Further, if $\left\{x_{n}\right\}$ converges to $z$ and the function $f(x)=p(x, T(x))$ is T-orbitally lower semicontinuous at $z$ with respect to $x_{0}$, then $z \in F(T)$. 
Proof. Let $x_{0}$ be a given point in $X$. Since $T\left(x_{0}\right) \in P_{c l}(X)$, we can choose $x_{1} \in T\left(x_{0}\right)$ such that

$$
\begin{aligned}
& \psi\left(p\left(x_{0}, x_{1}\right)\right) \leq p\left(x_{0}, T\left(x_{0}\right)\right), \\
& p\left(x_{1}, T\left(x_{1}\right)\right) \leq \phi\left(p\left(x_{0}, x_{1}\right)\right) .
\end{aligned}
$$

As before by continuing this way, we can obtain a sequence $\left\{x_{n}\right\}$ in $X$ such that $x_{n+1} \in T\left(x_{n}\right)$ which satisfies

$$
\begin{gathered}
\psi\left(p\left(x_{n}, x_{n+1}\right)\right) \leq p\left(x_{n}, T\left(x_{n}\right)\right), \\
p\left(x_{n+1}, T\left(x_{n+1}\right)\right) \leq \phi\left(p\left(x_{n}, x_{n+1}\right)\right) .
\end{gathered}
$$

By (47), we have

$$
p\left(x_{n+1}, T\left(x_{n+1}\right)\right) \leq \frac{\phi\left(p\left(x_{n}, x_{n+1}\right)\right)}{\psi\left(p\left(x_{n}, x_{n+1}\right)\right)} p\left(x_{n}, T\left(x_{n}\right)\right),
$$

for all $n \geq 0$. We define $\mu:[0, \infty) \rightarrow[0, \infty)$ by $\mu(t)=$ $\phi(t) / \psi(t)$ for all $t \in[0, \infty)$. Then by the definitions of $\phi$ and $\psi$, it follows that $\mu(t)<1$ for all $t \in[0, \infty)$, and $\lim \sup _{t \rightarrow r^{+}} \mu(t)<1$ for all $r \in[0, \infty)$. From (48), we have

$$
p\left(x_{n+1}, T\left(x_{n+1}\right)\right) \leq \mu\left(p\left(x_{n}, x_{n+1}\right)\right) p\left(x_{n}, T\left(x_{n}\right)\right) .
$$

As $\mu(t)<1$, so we have

$$
p\left(x_{n+1}, T\left(x_{n+1}\right)\right)<p\left(x_{n}, T\left(x_{n}\right)\right),
$$

for all $n \geq 0$. Also,

$$
\begin{aligned}
\phi\left(p\left(x_{n}, x_{n+1}\right)\right) & <\psi\left(p\left(x_{n}, x_{n+1}\right)\right) \\
& \leq p\left(x_{n}, T\left(x_{n}\right)\right) \leq \phi\left(p\left(x_{n-1}, x_{n}\right)\right) .
\end{aligned}
$$

By nondecreasing $\phi$, it follows that

$$
p\left(x_{n}, x_{n+1}\right)<p\left(x_{n-1}, x_{n}\right)
$$

for all $n \geq 0$. Thus, $\left\{p\left(x_{n}, T\left(x_{n}\right)\right)\right\}$ and $\left\{p\left(x_{n}, x_{n+1}\right)\right\}$ are (strictly) decreasing sequences of positive real numbers. Consequently, there exist $\alpha, \beta \geq 0$ such that $\left\{p\left(x_{n}, T\left(x_{n}\right)\right)\right\}$ converges to $\alpha$ and $\left\{p\left(x_{n}, x_{n+1}\right)\right\}$ converges to $\beta$. Now, by taking upper limit as $n \rightarrow \infty$ in (49), we have

$$
\alpha \leq \limsup _{n \rightarrow \infty} \mu\left(p\left(x_{n}, x_{n+1}\right)\right) \alpha,
$$

which implies $\alpha=0$; that is, $\lim _{n \rightarrow \infty} p\left(x_{n}, T\left(x_{n}\right)\right)=0$.

Now we show that $\left\{x_{n}\right\}$ is a Cauchy sequence. There exists a real number $k \in(0,1)$ such that, for a positive integer $n_{1}$ with $n \geq n_{1}$, we have

$$
p\left(x_{n}, T\left(x_{n}\right)\right) \leq k^{n-n_{0}} p\left(x_{n_{0}}, T\left(x_{n_{0}}\right)\right) .
$$

Clearly,

$$
\begin{aligned}
\phi\left(p\left(x_{n}, x_{n+1}\right)\right) & <\psi\left(p\left(x_{n}, x_{n+1}\right)\right) \leq p\left(x_{n}, T\left(x_{n}\right)\right) \\
& \leq k^{n-n_{0}} p\left(x_{n_{0}}, T\left(x_{n_{0}}\right)\right)
\end{aligned}
$$

for all $n>n_{1}$. Now

$$
\begin{aligned}
\psi & \left(p^{S}\left(x_{m}, x_{m+1}\right)\right) \\
& =\psi\left(2 p\left(x_{m}, x_{m+1}\right)-p\left(x_{m}, x_{m}\right)-p\left(x_{m+1}, x_{m+1}\right)\right) \\
& \leq \psi\left(2 p\left(x_{m}, x_{m+1}\right)+p\left(x_{m}, x_{m}\right)+p\left(x_{m+1}, x_{m+1}\right)\right) \\
& \leq 4 \psi\left(p\left(x_{m}, x_{m+1}\right)\right) \leq 4 k^{m-n} p\left(x_{n_{0}}, T\left(x_{n_{0}}\right)\right) .
\end{aligned}
$$

Thus

$$
\begin{aligned}
& \psi\left(p^{S}\left(x_{n}, x_{m}\right)\right) \\
& \leq \psi\left(p^{S}\left(x_{n}, x_{n+1}\right)+p^{S}\left(x_{n+1}, x_{n+2}\right)\right. \\
& \left.\quad+\cdots+p^{S}\left(x_{m-1}, x_{m}\right)\right) \\
& \leq 4\left[k+k^{2}+\cdots k^{m-n}\right] p\left(x_{n_{0}}, T\left(x_{n_{0}}\right)\right) \\
& \leq 4\left(\frac{k^{m}}{1-k}\right) p\left(x_{n_{0}}, T\left(x_{n_{0}}\right)\right),
\end{aligned}
$$

for all $m>n \geq n_{1}+1$. This implies that $\left\{x_{n}\right\}$ is a Cauchy sequence in the metric space $\left(O\left(T, x_{0}\right), p^{S}\right)$. By Lemma $4,\left\{x_{n}\right\}$ is a Cauchy sequence in $\left(O\left(T, x_{0}\right), p\right)$. Using arguments as in the proof of Theorem 7, we can show that the limit point of $\left\{x_{n}\right\}$ is a fixed point of $T$.

In same way, we can prove the following result.

Theorem 12. Let $X$ be a partial metric space and $T: X \rightarrow$ $P_{c l}(X)$ be a multivalued mapping. Suppose that there exist $\phi$ : $[0, \infty) \rightarrow[0, \infty), \psi:[0, \infty) \rightarrow(0, \infty)$ such that $\phi$ is nondecreasing and subadditive and they satisfy

$$
\begin{gathered}
\phi(t)<\psi(t) \quad \forall t \in[0, \infty), \\
\limsup _{t \rightarrow r^{+}} \frac{\phi(t)}{\psi(t)}<1 \quad \forall r \in[0, \infty) .
\end{gathered}
$$

If for any $x \in X$ there exists $y \in T(x)$ satisfying

$$
\begin{aligned}
& \psi(p(x, y)) \leq p(x, T(x)), \\
& p(y, T(y)) \leq \phi(p(x, y)),
\end{aligned}
$$

then, for each $x_{0} \in X$, there exists $\left\{x_{n}\right\}$ in $O\left(T, x_{0}\right)$ such that $\left\{x_{n}\right\}$ is a Cauchy sequence. Further, if $\left\{x_{n}\right\}$ converges to $z$ and the function $f(x)=p(x, T(x))$ is T-orbitally lower semicontinuous at $z$ with respect to $x_{0}$, then $z \in F(T)$.

The following result generalizes and extends Theorem 3.1 in [38] to partial metric spaces.

Corollary 13. Let $(X, p)$ be a partial metric space, and let $T$ : $X \rightarrow P_{c l}(X)$ be a multivalued mapping. If there exist constants $b, c \in(0,1)$ with $c<b$ such that, for any $x \in X$, there exists $y \in T(x)$ satisfying

$$
\begin{aligned}
& b p(x, y) \leq p(x, T(x)), \\
& p(y, T(y)) \leq c p(x, y),
\end{aligned}
$$


then, for each $x_{0} \in X$, there exists $\left\{x_{n}\right\}$ in $O\left(T, x_{0}\right)$ such that $\left\{x_{n}\right\}$ is a Cauchy sequence. Further, if $\left\{x_{n}\right\}$ converges to $z$ and the function $f(x)=p(x, T(x))$ is T-orbitally lower semicontinuous at $z$ with respect to $x_{0}$, then $z \in F(T)$.

The following corollary is an extension of [49] and in view of Corollary 3.2 in [38] is a special case of Theorem 10.

Corollary 14. Let $(X, p)$ be a partial metric space, and let $T$ : $X \rightarrow P_{c l}(X)$ be a multivalued mapping. If there exist constants $c \in(0,1)$ such that, for any $x \in X$, there exists $y \in T(x)$ satisfying

$$
p(y, T(y)) \leq c p(x, y)
$$

then, for each $x_{0} \in X$, there exists $\left\{x_{n}\right\}$ in $O\left(T, x_{0}\right)$ such that $\left\{x_{n}\right\}$ is a Cauchy sequence. Further, if $\left\{x_{n}\right\}$ converges to $z$ and the function $f(x)=p(x, T(x))$ is T-orbitally lower semicontinuous at $z$ with respect to $x_{0}$, then $z \in F(T)$.

Corollary 15. Let $X$ be a partial metric space and let $T: X \rightarrow$ $X$ be a self-mapping. Suppose that, there exist $\phi:[0, \infty) \rightarrow$ $[0, \infty), \psi:[0, \infty) \rightarrow(0, \infty)$ such that $\phi$ is nondecreasing and subadditive and they satisfy

$$
\begin{gathered}
\phi(t)<\psi(t) \quad \forall t \in[0, \infty), \\
\limsup _{t \rightarrow r^{+}} \frac{\phi(t)}{\psi(t)}<1 \quad \forall r \in[0, \infty) .
\end{gathered}
$$

If for any $x \in X$ there exists $T(x) \in X$ satisfying

$$
\begin{gathered}
\psi(p(x, T x)) \leq p(x, T x), \\
p\left(T x, T^{2} x\right) \leq \phi(p(x, T x)),
\end{gathered}
$$

then, for each $x_{0} \in X$, there exists $\left\{x_{n}\right\}$ in $O\left(T, x_{0}\right)$ such that $\left\{x_{n}\right\}$ is a Cauchy sequence. Further, if $\left\{x_{n}\right\}$ converges to $z$ and the function $f(x)=p(x, T x)$ is T-orbitally lower semicontinuous at $z$ with respect to $x_{0}$, then $T z=z$.

We remark that

(1) if $(X, p)$ is a complete partial metric space in Theorems 7 and 10, $T: X \rightarrow P_{c l}(X)$ is a multivalued mapping satisfying all the conditions of Theorems 7 and 10 , and the function $f(x):=p(x, T(x))$ is lower semicontinuous on $X$, then there exists $z$ in $X$ such that $z \in F(T)$.

(2) Theorems 7, 10, and 11 extend and generalize Theorems 2.1 and 2.4 in [47], Theorem 3.1 in [38], and Theorems $2.3,2.4,2.7$ and 2.8 in [41] to partial metric spaces.

\section{Application}

Let $U$ and $V$ be the Banach spaces with $W \subseteq U$ and $D \subseteq V$. Suppose that

$$
\begin{gathered}
\tau: W \times D \longrightarrow W, \quad g, h: W \times D \longrightarrow \mathbb{R}, \\
G: W \times D \times \mathbb{R} \longrightarrow \mathbb{R} .
\end{gathered}
$$

If we consider $W$ and $D$ as the state and decision spaces, respectively, then the problem of dynamic programming reduces to the problem of solving the functional equation

$$
q(x)=\sup _{y \in D}\{h(x, y)+G(x, y, q(\tau(x, y)))\}, \quad \text { for } x \in W .
$$

Equation (65) can be reformulated as

$$
q(x)=\sup _{y \in D}\{g(x, y)+G(x, y, q(\tau(x, y)))\}-b,
$$

for $x \in W$,

where $b>0$.

For more on problems of dynamic programming involving such functional equations, we refer the reader to $[25,50-$ 52].

We study the existence and uniqueness of the bounded solution of the functional equation (66) arising in dynamic programming in the setup of partial metric spaces.

Let $B(W)$ denote the set of all bounded real valued functions on $W$. For an arbitrary $h \in B(W)$, define $\|h\|=$ $\sup _{t \in W}|h(t)|$. Then $(B(W),\|\cdot\|)$ is a Banach space endowed with the metric $d$ defined as $d(h, k)=\sup _{t \in W}|h t-k t|$.

Now consider

$$
p_{B}(h, k)=d(h, k)+b=\sup _{t \in W}|h(t)-k(t)|+b,
$$

where $h, k \in B(W)$. Then $p_{B}$ is a partial metric on $B(W)$ (see also [53]).

We need the following two conditions.

$\left(\mathrm{A}_{1}\right) G$ and $g$ are bounded.

$\left(\mathrm{A}_{2}\right)$ For $x \in W, h \in B(W)$, and $b>0$, define

$$
K h(x)=\sup _{y \in D}\{g(x, y)+G(x, y, h(\tau(x, y)))\}-b .
$$

Moreover, assume that there exist mappings $\phi:[0, \infty) \rightarrow$ $[0, \infty)$ and $\psi:[0, \infty) \rightarrow(0, \infty)$ such that $\phi$ is nondecreasing and subadditive and they satisfy

$$
\begin{gathered}
\phi(t)<\psi(t), \quad \forall t \in[0, \infty), \\
\limsup _{t \rightarrow r^{+}} \frac{\phi(t)}{\psi(t)}<1, \quad \forall r \in[0, \infty) .
\end{gathered}
$$
that

Also for any $h \in B(W)$, there exists $K(h) \in B(W)$ such

$$
\begin{gathered}
\psi\left(p_{B}(h(x), K h(x))\right) \leq(h(x)-K h(x)), \\
\left|K h(x)-K^{2} h(x)\right| \leq \phi\left(p_{B}(h(x), K h(x))\right)-b
\end{gathered}
$$

hold for all $x \in W$.

Theorem 16. Assume that conditions $\left(A_{1}\right)$ and $\left(A_{2}\right)$ are satisfied. If $K(B(W))$ is a closed convex subspace of $B(W)$, then the functional equation (66) has a unique and bounded solution. 
Proof. Note that $\left(B(W), p_{B}\right)$ is a complete partial metric space. By $\left(A_{1}\right), K$ is a self-map of $B(W)$. By $(68)$ in $\left(A_{2}\right)$ it follows that for any $h \in B(W)$, there exists $K(h) \in B(W)$ such that

$$
\begin{gathered}
\psi\left(p_{B}(h(t), K h(t))\right) \leq(h(t)-K h(t)), \\
\left|K h(t)-K^{2} h(t)\right| \leq \phi\left(p_{B}(h(t), K h(t))\right)-b
\end{gathered}
$$

hold for all $t \in W$. Now, we have

$$
\begin{aligned}
& (h(t)-K h(t)) \\
& \quad=h(t)-\left[\sup _{y \in D}\{g(x, y)+G(x, y, h(\tau(x, y)))\}-b\right] \\
& \quad=h(t)-\left[\sup _{y \in D}\{g(x, y)+G(x, y, h(\tau(x, y)))\}\right]+b \\
& \quad \leq \sup _{t \in W} \mid h(t)-\left[\sup _{y \in D}\{g(x, y)+G(x, y, h(\tau(x, y)))\}\right]+b \\
& \quad=p_{B}(h(t), K h(t)) .
\end{aligned}
$$

Also

$$
\begin{aligned}
p_{B}\left(K^{2} h(t), K h(t)\right) & =\sup _{t \in W}\left|K^{2} h(t)-K h(t)\right|+b \\
& \leq \phi\left(p_{B}(h(t), K h(t))\right) .
\end{aligned}
$$

Note that the above inequalities are true for all $t \in W$, and, for any $h \in B(W)$, there exists $K(h) \in B(W)$ such that

$$
\begin{gathered}
\psi\left(p_{B}(h, K h)\right) \leq p_{B}(h, K h), \\
p_{B}\left(K^{2} h, K h\right) \leq \phi\left(P_{B}(h, K h)\right) .
\end{gathered}
$$

Therefore by Corollary 15, the map $K$ has a fixed point $h^{*}$; that is, $h^{*}(x)$ is a unique and bounded solution of functional equation (66).

\section{Conflict of Interests}

The authors declare that there is no conflict of interests regarding the publication of this paper.

\section{Acknowledgment}

The authors A. R. Khan and M. Abbas are grateful to King Fahd University of Petroleum and Minerals for supporting Research Project IN 121023.

\section{References}

[1] S. Banach, "Sur les operations dans les ensembles abstraits et leur application aux equations integrales," Fundamenta Mathematicae, vol. 3, pp. 133-181, 1922.

[2] T. L. Hicks, "Fixed point theorems for quasimetric spaces," Mathematica Japonica, vol. 33, no. 2, pp. 231-236, 1988.
[3] B. S. Choudhury and N. Metiya, "Coincidence point and fixed point theorems in ordered cone metric spaces," Journal of Advanced Mathematical Studies, vol. 5, no. 2, pp. 20-31, 2012.

[4] M. O. Olatinwo and M. Postolache, "Stability results of Jungcktype iterative processes in convex metric spaces," Applied Mathematics and Computation, vol. 218, no. 12, pp. 6727-6732, 2012.

[5] H. Aydi, W. Shatanawi, M. Postolache, Z. Mustafa, and N. Tahat, "Theorems for Boyd-Wong-type contractions in ordered metric spaces," Abstract and Applied Analysis, vol. 2012, Article ID 359054, 14 pages, 2012.

[6] H. Aydi, E. Karapinar, and M. Postolache, "Tripled coincidence point theorems for weak $\varphi$-contractions in partially ordered metric spaces," Fixed Point Theory and Applications, vol. 2012, article 44, 12 pages, 2012.

[7] S. Chandok and M. Postolache, "Fixed point theorem for weakly Chatterjea-type cyclic contractions," Fixed Point Theory and Applications, vol. 2013, article 28, 9 pages, 2013.

[8] B. S. Choudhury, N. Metiya, and M. Postolache, "A generalized weak contraction principle with applications to coupled coincidence point problems," Fixed Point Theory and Applications, vol. 2013, article 152, 21 pages, 2013.

[9] W. Shatanawi and M. Postolache, "Common fixed point results for mappings under nonlinear contraction of cyclic form in ordered metric spaces," Fixed Point Theory and Applications, vol. 2013, article 60, 13 pages, 2013.

[10] W. Shatanawi and M. Postolache, "Common fixed point theorems for dominating and weakannihilator mappings in ordered metric spaces," Fixed Point Theory and Applications, vol. 2013, article 271, 2013.

[11] H. Aydi, M. Postolache, and W. Shatanawi, "Coupled fixed point results for $(\psi, \phi)$-weakly contractive mappings in ordered $G$ metric spaces," Computers \& Mathematics with Applications, vol. 63, no. 1, pp. 298-309, 2012.

[12] S. Chandok, Z. Mustafa, and M. Postolache, "Coupled common fixed point theorems for mixed g-monotone mappings in partially ordered G-metric spaces," University Politehnica of Bucharest Scientific Bulletin Series A, vol. 75, no. 4, pp. 11-24, 2013.

[13] W. Shatanawi and M. Postolache, "Some fixed-point results for a $G$-weak contraction in G-metric spaces," Abstract and Applied Analysis, vol. 2012, Article ID 815870, 19 pages, 2012.

[14] W. Shatanawi and A. Pitea, "Fixed and coupled fixed point theorems of omega-distance for nonlinear contraction," Fixed Point Theory and Applications, vol. 2013, article 275, 16 pages, 2013.

[15] W. Shatanawi and A. Pitea, "Omega-distance and coupled fixed point in G-metric spaces," Fixed Point Theory and Applications, vol. 2013, article 208, 15 pages, 2013.

[16] H. Aydi, "Fixed point results for weakly contractive mappings in ordered partial metric spaces," Journal of Advanced Mathematical Studies, vol. 4, no. 2, pp. 1-12, 2011.

[17] W. Shatanawi and M. Postolache, "Coincidence and fixed point results for generalized weak contractions in the sense of Berinde on partial metric spaces," Fixed Point Theory and Applications, vol. 2013, article 54, 17 pages, 2013.

[18] W. Shatanawi and A. Pitea, "Some coupled fixed point theorems in quasi-partial metric spaces," Fixed Point Theory and Applications, vol. 2013, article 153, 15 pages, 2013.

[19] M. Grabiec, "Fixed points in fuzzy metric spaces," Fuzzy Sets and Systems, vol. 27, no. 3, pp. 385-389, 1988. 
[20] K. Menger, "Statistical metrics," Proceedings of the National Academy of Sciences of the United States of America, vol. 28, pp. 535-537, 1942.

[21] R. H. Haghi, M. Postolache, and Sh. Rezapour, "On T-stability of the Picard iteration for generalized $\varphi$-contraction mappings," Abstract and Applied Analysis, vol. 2012, Article ID 658971, 7 pages, 2012.

[22] M. A. Miandaragh, M. Postolache, and Sh. Rezapour, "Some approximate fixed point results for generalized $\alpha$-contractive mappings," Scientific Bulletin A, vol. 75, no. 2, pp. 3-10, 2013.

[23] M. A. Miandaragh, M. Postolache, and Sh. Rezapour, "Approximate fixed points of generalized convex contractions," Fixed Point Theory and Applications, vol. 2013, article 255, 8 pages, 2013.

[24] S. G. Matthews, "Partial metric topology," in Proceedings of the 8th Summer Conference on General Topology and Applications, vol. 728 of Annals of the New York Academy of Sciences, pp. 183197, 1994.

[25] C. D. Bari and P. Vetro, "Fixed points for weak $\varphi$-contractions on partial metric spaces," International Journal of Engineering, Contemporary Mathematics and Sciences, vol. 1, pp. 5-13, 2011.

[26] D. Paesano and P. Vetro, "Suzuki's type characterizations of completeness for partial metric spaces and fixed points for partially ordered metric spaces," Topology and its Applications, vol. 159, no. 3, pp. 911-920, 2012.

[27] L. J. Ćirić, B. Samet, H. Aydi, and C. Vetro, "Common fixed points of generalized contractions on partial metric spaces and an application," Applied Mathematics and Computation, vol. 218, no. 6, pp. 2398-2406, 2011.

[28] R. Heckmann, "Approximation of metric spaces by partial metric spaces," Applied Categorical Structures, vol. 7, no. 1-2, pp. 71-83, 1999.

[29] S. Romaguera, "A Kirk type characterization of completeness for partial metric spaces," Fixed Point Theory and Applications, vol. 2010, Article ID 493298, 6 pages, 2010.

[30] S. Romaguera and O. Valero, "A quantitative computational model for complete partial metric spaces via formal balls," Mathematical Structures in Computer Science, vol. 19, no. 3, pp. 541-563, 2009.

[31] M. P. Schellekens, "The correspondence between partial metrics and semivaluations," Theoretical Computer Science, vol. 315, no. 1, pp. 135-149, 2004.

[32] R. H. Haghi, Sh. Rezapour, and N. Shahzad, "Be careful on partial metric fixed point results," Topology and its Applications, vol. 160, no. 3, pp. 450-454, 2013.

[33] M. Jleli, E. Karapınar, and B. Samet, "Further remarks on fixedpoint theorems in the context of partial metric spaces," Abstract and Applied Analysis, vol. 2013, Article ID 715456, 6 pages, 2013.

[34] B. Samet, C. Vetro, and F. Vetro, "From metric spaces to partial metric spaces," Fixed Point Theory and Applications, vol. 2013, article 5, 11 pages, 2013.

[35] H. K. Nashine and Z. Kadelburg, "Cyclic contractions and fixed point results via control functions on partial metric spaces," International Journal of Analysis, vol. 2013, Article ID 726387, 9 pages, 2013.

[36] H. K. Nashine, Z. Kadelburg, and S. Radenović, "Fixed point theorems via various cyclic contractive conditions in partial metric spaces," De L'Institut Mathematique, vol. 93, no. 107, pp. 69-93, 2013.

[37] H. Aydi, M. Abbas, and C. Vetro, "Partial Hausdorff metric and Nadler's fixed point theorem on partial metric spaces," Topology and its Applications, vol. 159, no. 14, pp. 3234-3242, 2012.
[38] Y. Feng and S. Liu, "Fixed point theorems for multi-valued contractive mappings and multi-valued Caristi type mappings," Journal of Mathematical Analysis and Applications, vol. 317, no. 1, pp. 103-112, 2006.

[39] D. Klim and D. Wardowski, "Fixed point theorems for setvalued contractions in complete metric spaces," Journal of Mathematical Analysis and Applications, vol. 334, no. 1, pp. 132139, 2007.

[40] A. Latif and A. A. N. Abdou, "Fixed point results for generalized contractive multimaps in metric spaces," Fixed Point Theory and Applications, vol. 2009, Article ID 432130, 16 pages, 2009.

[41] A. Nicolae, "Fixed point theorems for multi-valued mappings of Feng-Liu type," Fixed Point Theory, vol. 12, no. 1, pp. 145-154, 2011.

[42] I. Altun and H. Simsek, "Some fixed point theorems on dualistic partial metric spaces," Journal of Advanced Mathematical Studies, vol. 1, no. 1-2, pp. 1-8, 2008.

[43] M. Abbas and T. Nazir, "Common fixed point of a power graphic contraction pair in partial metric spaces endowed with a graph," Fixed Point Theory and Applications, vol. 2013, article 20,8 pages, 2013.

[44] M. Abbas and T. Nazir, "Fixed point of generalized weakly contractive mappings in ordered partial metric spaces," Fixed Point Theory and Applications, vol. 2012, article 1, 19 pages, 2012.

[45] M. A. Bukatin and S. Y. Shorina, "Partial metrics and cocontinuous valuations," in Foundations of Software Science and Computation Structure, M. Nivat et al., Ed., vol. 1378 of Lecture Notes in Computer Science, pp. 125-139, Springer, Berlin, Germany, 1998.

[46] M. Berinde and V. Berinde, "On a general class of multi-valued weakly Picard mappings," Journal of Mathematical Analysis and Applications, vol. 326, no. 2, pp. 772-782, 2007.

[47] Y. J. Cho, S. Hirunworakit, and N. Petrot, "Set-valued fixedpoint theorems for generalized contractive mappings without the Hausdorff metric," Applied Mathematics Letters, vol. 24, no. 11, pp. 1959-1967, 2011.

[48] L. Ćirić, "Fixed point theorems for multi-valued contractions in complete metric spaces," Journal of Mathematical Analysis and Applications, vol. 348, no. 1, pp. 499-507, 2008.

[49] S. B. Nadler, Jr., "Multi-valued contraction mappings," Pacific Journal of Mathematics, vol. 30, pp. 475-488, 1969.

[50] R. Baskaran and P. V. Subrahmanyam, "A note on the solution of a class of functional equations," Applicable Analysis, vol. 22, no. 3-4, pp. 235-241, 1986.

[51] R. Bellman and E. S. Lee, "Functional equations in dynamic programming," Aequationes Mathematicae, vol. 17, no. 1, pp. 1$18,1978$.

[52] P. C. Bhakta and S. Mitra, "Some existence theorems for functional equations arising in dynamic programming," Journal of Mathematical Analysis and Applications, vol. 98, no. 2, pp. 348-362, 1984.

[53] M. Abbas and B. Ali, "Fixed point of Suzuki-Zamfirescu hybrid contractions in partial metric spaces via partial Hausdorff metric," Fixed Point Theory and Applications, vol. 2013, article 21, 16 pages, 2013. 


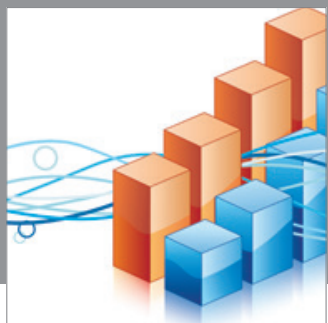

Advances in

Operations Research

mansans

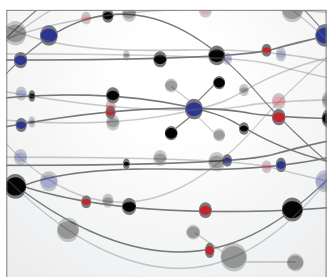

The Scientific World Journal
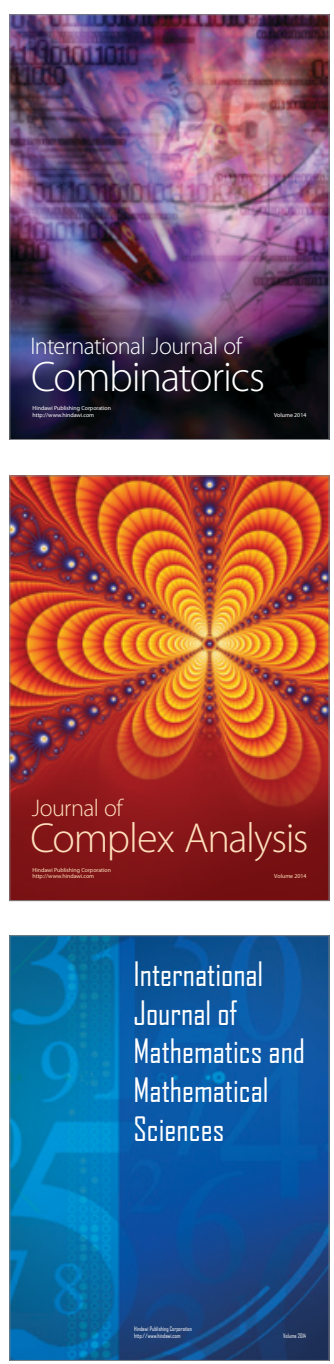
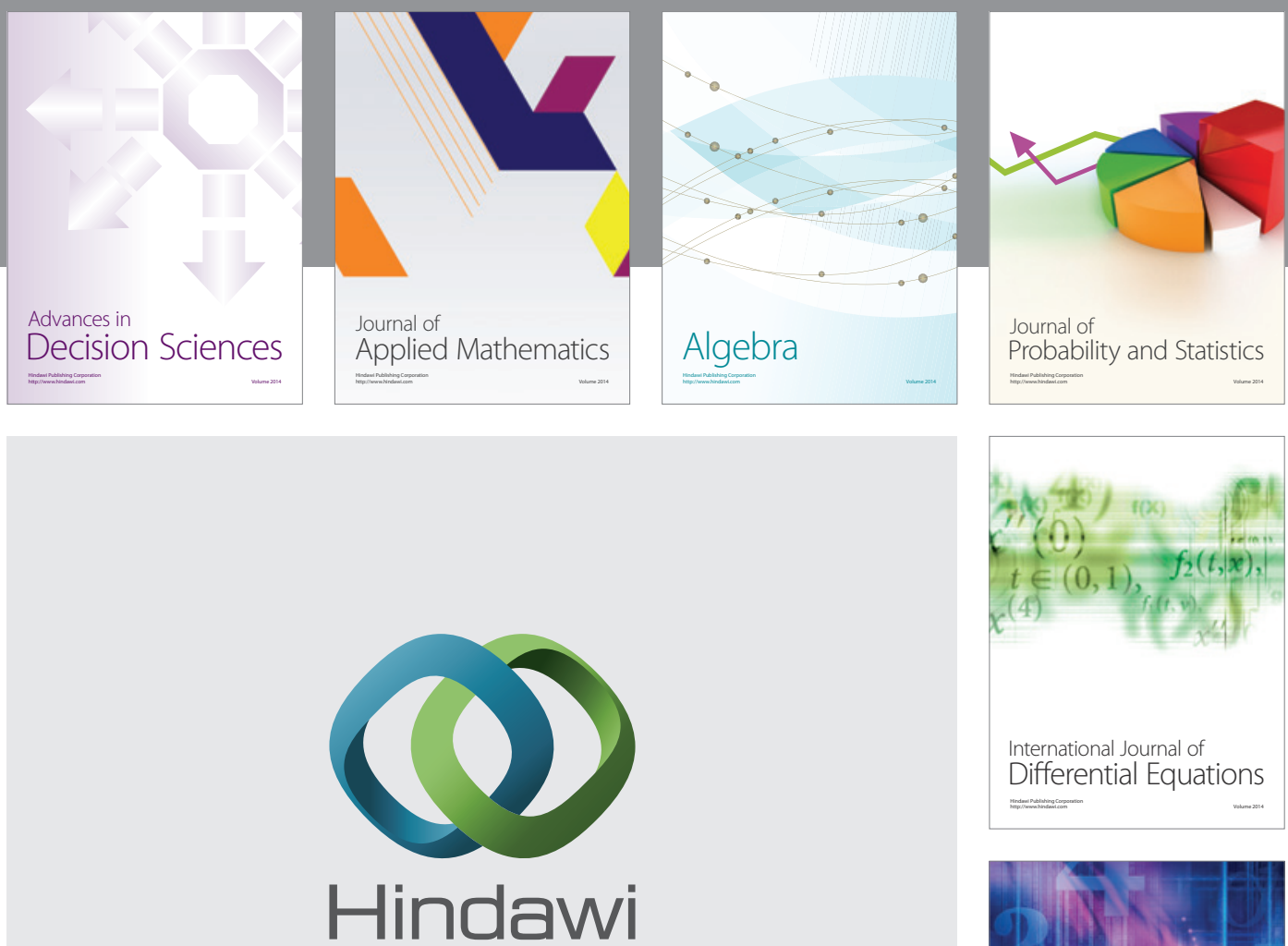

Submit your manuscripts at http://www.hindawi.com
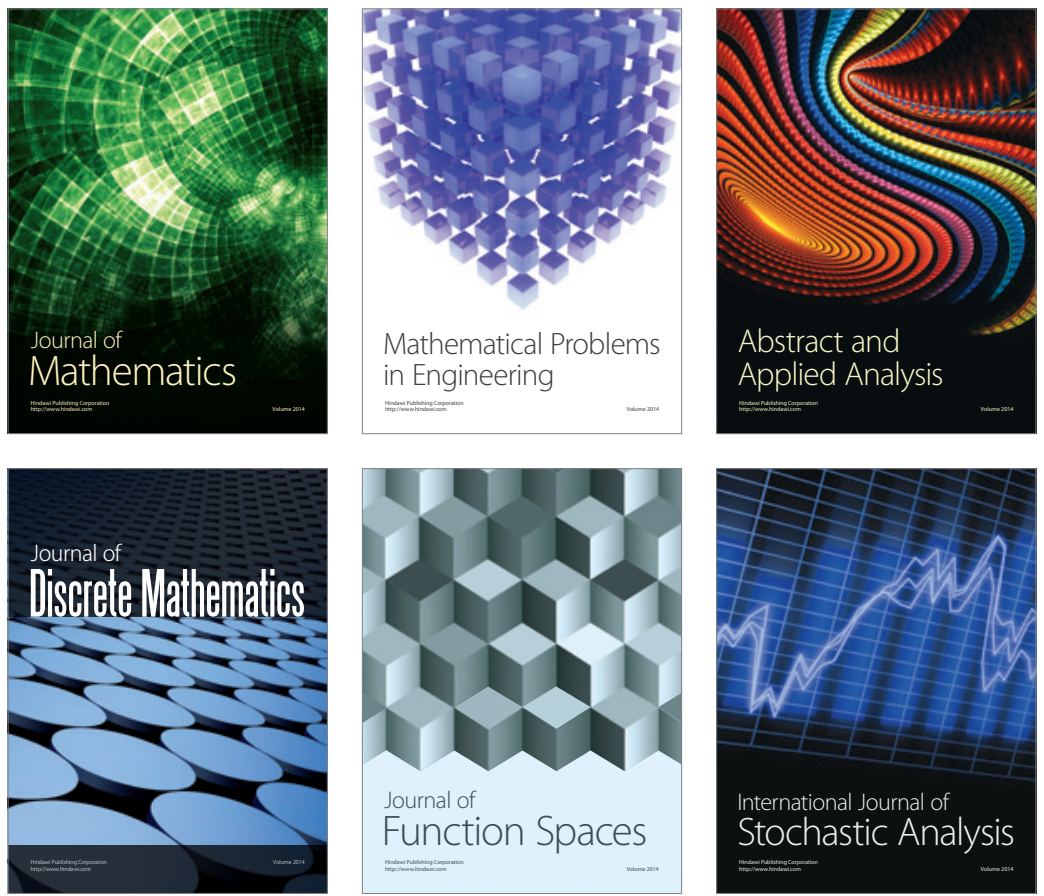

Journal of

Function Spaces

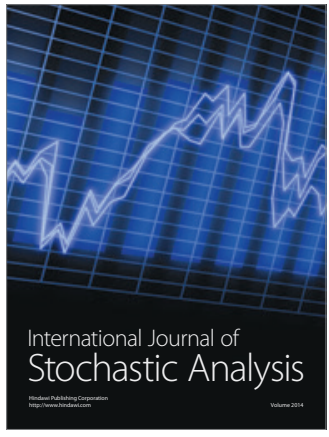

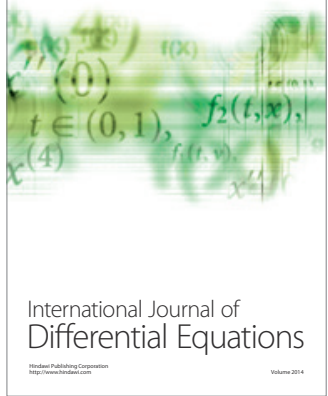
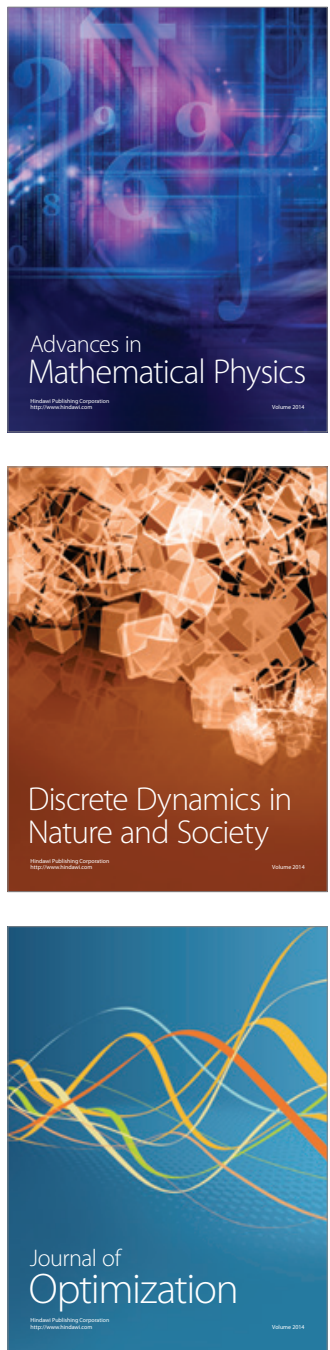